\title{
Trade, Technical Progress and the Environment: the Role of a Unilateral Green Tax on Consumption
}

\author{
Daniela Marconi ${ }^{\mathrm{a}^{*}}$
}

${ }^{a}$ Bank of Italy

\begin{abstract}
The paper proposes a two-country general equilibrium model of endogenous growth and trade between two regions, North and South, with different environmental standards. Pollution is a byproduct of consumption and in order to abate it the northern region unilaterally imposes a green tax on consumption. As the tax affects domestic demand of consumer goods according to their pollution intensities, regardless of where those goods are produced, the model shows that such a unilateral environmental policy can increase the speed of technological change and pollution abatement in both regions.
\end{abstract}

JEL classifications: 030, F14, F18

Keywords: trade, environment, consumption externality, technological change

\section{Introduction}

The interaction between trade and environmental regulation has generated a large body of literature which, within classical static models of international trade, has mainly focused on the impact of environmental regulation on comparative advantages (Copeland and Taylor, 2003 and 2004). According to this literature richer countries, which have higher demands for environmental quality, tend to impose more stringent environmental regulations in order to abate pollution. Pollution abatement, however, imposing extra costs on domestic firms, affects international competitiveness, eventually reversing

\footnotetext{
* Corresponding author: Bank of Italy, International Economic Analysis and Relations Department, Via Nazionale 91, 00184, Rome, Italy. Fax: (+39)06-4792-4118. E-mail: daniela.marconi@bancaditalia.it. I am grateful to Ignazio Musu for comments and suggestions on earlier drafts of this paper. I also wish to thank Tony Venables, the seminar participants at the University of Oxford and at the 2009 APJAE Symposium in Hong Kong for their observations and valuable discussions and an anonymous referee for helpful comments. The usual disclaimer applies. The views expressed in this article are those of the author and do not involve the responsibility of the Bank of Italy.
} 
comparative advantages and inducing dirty sectors to concentrate in poorer countries with weaker environmental standards (pollution havens).

Models of environmental policy and technological change, in turn, have been mainly developed in closed economy frameworks where pollution is treated either as a complementary input (Ricci, 2007) or as a pure production externality (Peretto, 2008). In both cases pollution abatement (induced by taxation) imposes a trade-off between technological change directed to productivity improvements and technological progress directed to pollution abatement; by shifting resources from the former to the latter longrun growth might reduce, although would still be sustainable thanks to technological progress in pollution abatement.

There are very few models that link the three aspects, trade, endogenous technological change and environmental regulation. Di Maria and Smulders (2004) show that if the northern technology diffuses to the South, one of the possible outcomes of trade is that the North, which by hypothesis has a comparative advantage in the clean sector, develops more environmentally friendly technologies and the South, which, in turn, has a comparative advantage in the polluting sector, reduces pollution. Such an outcome, however, depends crucially on technology diffusion and on the degree of substitution between clean and pollution-intensive goods; if goods are hardly substitutable, conclusions are reversed.

The aim of this paper is to extend the literature on endogenous technological change and the environment in an open economy to consider the case of countries with asymmetric environmental regulation. The ultimate goal is to feed into the current debate on the effectiveness of policy actions to abate pollution undertaken in isolation in a non-cooperative globalized world.

To this end, I propose a general equilibrium model of trade, pollution and technological change borrowing from the cited literature. There are two regions, North (N) and South $(\mathrm{S})$, and both regions produce a differentiated set of polluting consumption goods. I start from the assumption that the richer region $(\mathrm{N})$ has environmental concerns and wishes to abate pollution, while the poorer one does not have such a concern (S). If, in order to abate pollution, $\mathrm{N}$ imposes a unilateral tax on domestic production it would impose an extra cost on domestic firms, thereby undermining their international competitiveness. In order to eliminate such a trade-off this paper considers pollution as a by-product of consumption and proposes to study the effects of a unilateral green tax on consumption. A tax on domestic consumption of polluting goods by shifting the burden on consumers, would affect the demand schedule for goods according to their pollution intensity, regardless of where those goods are produced. As a result, world consumption and production of polluting goods are reduced unless technological change compensates.

As in previous works (Di Maria and Smulders, 2004, Peretto, 2008 and Ricci, 2007), I suppose that research and development (R\&D) is directed to two sorts of innovations: pollution abatement and cost-reducing innovations. Goods that meet higher environmental standards will have a larger market share in the northern region. Pollution abatement is obtained by relocating resources to R\&D. The model shows that: (a) if trade must be balanced, then the northern region can impose a green tax on consumption as long as its income is large enough; (b) as the green tax affects both profits and the 
terms of trade it can spur innovation in both countries; and (c) pollution levels might be permanently reduced in both regions.

The assumption that the social cost of pollution can be internalized by taxing consumption relies on both empirical and theoretical considerations and requires a brief discussion. On the empirical ground, Milito and Gagnon (2008) show that in mature economies, such as Canada, households' consumption generates, both directly, through direct consumption of fuel (motor fuel and residential fuel), and indirectly, through the emissions resulting from the production of goods and services purchased, about half of the total national greenhouse gas emissions. Hence, although pollution due to consumption is certainly not exhaustive, it could tackle half of the problem, bringing to attention the role of taxation in shifting consumption towards more sustainable products, and eventually accelerating the introduction of new technologies (Albrect, 2006).

On the theoretical ground, the political economy literature has recently shown that in an open economy a regulator captured by polluting industries can more easily abate pollution by regulating consumer-generated emissions (McAusland, 2008 and Schleich, 1999). As domestic and foreign goods will be affected in the same fashion according to their pollution intensities, we could further argue that this kind of unilateral action can indeed overcome free-riding and carbon leakage problems.

The literature on trade and the environment generally considers economies with two sectors, a dirty and a clean sector, and uses taxation to shift production from the former to the latter within national boundaries, eventually reversing international specialization (Copeland and Taylor, 1995 and 2003). This means that in this framework there is no guarantee that the direction of technological change is towards pollution abatement in dirty sectors. In fact, when countries have different environmental standards, polluting emissions from production or consumption are eventually reduced where standards are more stringent but increased elsewhere, where standards are lower. On the contrary, here, by taxing consumption, pollution is internalized no matter where the goods are produced, somewhat leveling the playing field and impacting worldwide pollution and technological change. However, for such an action to be successful the market size is crucial, in that only a large regulated market can offer sizeable incentives to invest in abatement technologies thereby inducing pollution abatement worldwide.

The paper does not concern optimal environmental taxation; rather its aim is to show, by means of a simplified general equilibrium model, that it is indeed possible to produce positive spillovers in terms of world pollution, technological change, and welfare by unilaterally imposing a green tax on consumption. In this respect the contribution of the paper to the existing literature is twofold. First, to my knowledge, this is the first attempt to model pollution as a by-product of consumption within an endogenous growth framework with international trade, and, secondly, as a result of that, this is the first time in which it is possible to analyze the effects of a unilateral environmental policy action overcoming the trade-off between unilateral abatement policies and international competitiveness of domestic firms.

The paper is organized as follow: section 2 describes the model and the equilibrium. Section 3 describes the government policy and computes the balanced growth path. Section 4 presents the model's implications for world pollution. Section 5 discusses welfare. Section 6 concludes. 


\section{The Model}

\subsection{Pollution}

Let us consider a two-country world: North $(\mathrm{N})$ and South $(\mathrm{S})$. Each economy is populated by a finite number of identical firms, $I_{i}(i=\mathrm{N}, \mathrm{S})$, which produce differentiated consumption goods in monopolistic competition. The number of goods is fixed countable. All the goods are traded between the two countries. Households in the two countries love variety and wish to consume all the available varieties, domestic firms produce $I_{N}$ goods, foreign firms $I_{S}$, therefore the total number of consumption goods is $I=I_{N}+I_{S}$.

At time $\tau$ each unit of good $j$ consumed produces a level of pollution $Z_{j \tau}^{-\phi}$, where $Z_{j \tau}$ is the stock of pollution abatement technology embedded in good $j$ at time $\tau$ and $\phi, 0<\phi<1$, is the elasticity of pollution abatement. Aggregate pollution in region $i$ at time $\tau$ is:

$$
P_{i \tau}=\sum_{j=1}^{I_{N}+I_{S}} Z_{j \tau}^{-\phi} x_{j \tau}^{i}
$$

$x_{j \tau}^{i}$ is the quantity of $j$-th good consumed by the representative household in region $i$. Pollution is local and can be reduced either by reducing $x_{j \tau}^{i}$ or by increasing $Z_{j \tau}$. We assume that pollution is a concern only for the citizens in the richer northern region. To abate pollution, the northern government imposes a green tax on consumption proportional to the pollution intensity of each good:

$$
H_{j \tau}=h_{j \tau} \frac{P_{j \tau}}{x_{j \tau}}=h_{j \tau} Z_{j \tau}^{-\phi}
$$

$h_{j \tau}$ is the tax rate on the $j$-th good at time $\tau .^{1}$

\subsection{Consumption}

At time $\tau$ the representative household in $N$ maximizes utility over an infinite horizon

$$
U_{N \tau}=\int_{t}^{\infty} e^{-\rho(\tau-t)}\left\{\log \left[\sum_{j=1}^{I_{N}+I_{S}}\left(x_{j \tau}^{N}\right)^{\alpha}\right]^{1 / \alpha}-\varphi \log D\left(P_{N \tau}\right)\right\} d \tau,
$$

\footnotetext{
${ }^{1}$ The assumption that the southern region has no environmental concerns is a simplification used here to stress the need of a unilateral policy action. More in general, the question of whether and why poorer countries tend to have lower environmental concerns is usually addressed in the literature by means of the "environmental Kuznets curve" hypothesis (Copeland and Taylor, 2004). Also, here we do not consider transboundary pollution to keep the analysis as simple as possible; nonetheless, as the green tax on consumption has the potential to reduce pollution per unit of consumption in both regions, this policy turns out to be even more beneficial in the case of transboundary pollution.
} 
$0<\alpha<1 ; 0<\varphi<1$.

Subject to a dynamic budget constraint

$$
\dot{B}_{N \tau}=r_{N \tau} B_{N \tau}+w_{N \tau} L_{N}+G_{N \tau}-Y_{N \tau} .
$$

Households have Dixit-Stiglitz preferences over the diversified consumption goods $x_{j \tau}^{i}$ and get disutility from the damages caused by aggregate pollution $\left(D\left(P_{N \tau}\right)\right)$; however, they do not internalize their contribution to it. $B_{N}$ is asset holdings, the dot indicate time derivative, i.e. $\dot{B}=d B / d \tau, r_{N}$ is the interest rate, $L_{N}$ is the labor force, in fixed supply, $w_{N}$ is the wage rate, $G_{N}$ are government transfers (green tax revenues are rebated lump sum to northern citizens) and $Y_{N}$ is consumption expenditure, $Y_{N \tau}=\sum_{j=1}^{I_{N}+I_{S}}\left(P_{j \tau}^{N}+h_{j \tau} Z_{j \tau}^{-\phi}\right) x_{j \tau}^{N}$; $p_{j \tau}^{N}$ is the price of good $j$ in country $\mathrm{N}$ at time $\tau$.

In $\mathrm{S}$ the government levies no taxes, hence, $G_{S}=0$. Households have same preferences as in $\mathrm{N}$ for consumption but do not care about pollution, therefore, they maximize

$$
\begin{aligned}
& U_{N \tau}=\int_{t}^{\infty} e^{-\rho(\tau-t)}\left\{\log \left[\sum_{j=1}^{I_{N}+I_{S}}\left(x_{j \tau}^{S}\right)^{\alpha}\right]^{1 / \alpha}\right\} d \tau \\
& \text { s.t. } \dot{B}_{S \tau}=r_{N \tau} B_{S \tau}+w_{S \tau} L_{S}-Y_{S \tau} \text {; with } Y_{S \tau}=\sum_{j=1}^{I_{N}+I_{S}} p_{j \tau}^{S} x_{j \tau}^{S} .
\end{aligned}
$$

Where $x_{j \tau}^{S}$ and $p_{j \tau}^{S}$ are, respectively, the quantity consumed and the price of good $\mathrm{j}$ in $\mathrm{S}$, all the other variables have the same meaning as before and the subscript $\mathrm{S}$ indicates that they refer to region $\mathrm{S}$. All the values are expressed in a common currency which grows at the rate of growth of world tradable output.

Households' maximization in $\mathrm{N}$ and $\mathrm{S}$ yields the following demand functions for $\operatorname{good} j$ :

$$
\begin{aligned}
& x_{j \tau}^{N}=Y_{N \tau} \frac{\left(p_{j \tau}^{N}+h_{j \tau} Z_{j \tau}^{-\phi}\right)^{-1 /(1-\alpha)}}{\sum_{j=1}^{I_{N}+I_{S}}\left(p_{j \tau}^{N}+h_{j \tau} Z_{j \tau}^{-\phi}\right)^{-\alpha /(1-\alpha)}} \\
& x_{j \tau}^{S}=Y_{S \tau} \frac{\left(p_{j \tau}^{S}\right)^{-1 /(1-\alpha)}}{\sum_{j=1}^{I_{N}+I_{S}}\left(p_{j \tau}^{S}\right)^{-\alpha /(1-\alpha)}} .
\end{aligned}
$$

$1 /(1-\alpha)>1$ is the constant elasticity of substitution between varieties, the elasticity with respect to income is one. Households' optimal expenditure plans also require the Euler equation to hold in each country:

$$
\frac{\dot{Y}_{i}}{Y_{i}}=r_{i}-\rho
$$


The growth rate of expenditures is equal to the difference between the interest rate $r$ and the subjective discount rate, $\rho$.

\subsection{Production}

Each differentiated good is produced using labor and firm-specific know-how:

$$
x_{i j}=A_{i j}^{\beta} L_{i j} .
$$

$A_{i j}$ is the knowledge stock of process innovations of firm $j$ in country $i$ which determines labor productivity. ${ }^{2}$ Firms operate in Bertrand's monopolistic competition and, as they face different demand functions in the two countries, they can price discriminate. Each firm maximizes profits:

$$
\begin{aligned}
& \max _{p_{j \tau}^{N}, p_{j \tau}^{S}} \Pi_{i j \tau}=p_{j \tau}^{N} x_{j \tau}^{N}+p_{j \tau}^{S} x_{j \tau}^{S}-w_{i \tau} A_{i j \tau}^{-\beta}\left(x_{j \tau}^{N}+x_{j \tau}^{S}\right) \\
& \text { s.t. } x_{j \tau}^{N}=\frac{Y_{N \tau}\left(p_{j \tau}^{N}+h_{j \tau} Z_{j \tau}^{-\phi}\right)^{-1 /(1-\alpha)}}{\sum_{j=1}^{I_{N}+I_{S}}\left(p_{j \tau}^{N}+h_{j \tau} Z_{j \tau}^{-\phi}\right)^{-\alpha /(1-\alpha)}} \\
& \text { and } x_{j \tau}^{S}=\frac{Y_{S \tau}\left(p_{j \tau}^{S}\right)^{-1 /(1-\alpha)}}{\sum_{j=1}^{I_{N}+I_{S}}\left(p_{j \tau}^{S}\right)^{-\alpha /(1-\alpha)}} .
\end{aligned}
$$

Maximization yields the following pricing strategy:

$$
\begin{aligned}
& \hat{p}_{j \tau}^{N}=\frac{w_{i \tau} A_{i j \tau}^{-\beta}+(1-\alpha) h_{j \tau} Z_{j \tau}^{-\phi}}{\alpha} \\
& \hat{p}_{j \tau}^{S}=\frac{w_{i \tau} A_{i j \tau}^{-\beta}}{\alpha} .
\end{aligned}
$$

Firms set the price equal to a fixed mark-up over the marginal cost. In $\mathrm{N}$ differentiated goods are sold for a higher unit price compared to $\mathrm{S}$. The green tax, in fact, acts as if firms face higher marginal costs when selling the good in N. The higher the pollution intensity, the lower the demand and the higher the price charged in $\mathrm{N}$ for that good.

To simplify the analysis, we assume that firms are symmetric within each region, but not between them. Therefore we set $A_{i j}=\frac{1}{I_{i}} \sum_{j=1}^{I_{i}} A_{i j}=\bar{A}_{i}$ and $Z_{i j}=\frac{1}{I_{i}} \sum_{j=1}^{I_{i}} Z_{i j}=\bar{Z}_{i}$;

\footnotetext{
${ }^{2}$ Here process innovations can be interpreted either as quality improvements or as cost reductions (for a discussion on this topic see Acemoglu, 2009).
} 
that is, cost reducing and pollution abatement technologies associated to each good are equal to the region's average levels. By increasing $\bar{A}_{i}$ the average labor productivity in region $i$ increases and by increasing $\bar{Z}_{i}$ the average pollution intensity of consumption goods produced in region $i$ declines, $A$ and $Z$ can be increased only through costly R\&D activities, as it will be discussed later on.

In order to pin down the wage rate, we assume that in each country there exists a wage setting agreement such that wages are linked to the average domestic labor productivity in the $\mathrm{X}$ sector; that is, $w_{N \tau}=c_{N} \bar{A}_{N \tau}^{\beta}$ and $w_{S \tau}=c_{S} \bar{A}_{S \tau}^{\beta}$, where $0<c_{i} \leq 1$. Without loss of generality, we can further assume that the two shares are the same across the two countries, and set them equal to $c .^{3}$

Using the fact that firms are symmetric within each country, we can write the maximum level of profits of a typical firm in $\mathrm{N}$ as:

$$
\hat{\Pi}_{N j \tau}=\frac{(1-\alpha)}{I_{N}}\left(s_{N \tau}^{N} Y_{N \tau}+s_{N \tau}^{S} Y_{S \tau}\right),
$$

where $s_{N \tau}^{N} \equiv \frac{I_{N}\left(c+h_{N \tau} \bar{Z}_{N \tau}^{-\phi}\right)^{-\alpha /(1-\alpha)}}{I_{N}\left(c+h_{N \tau} Z_{N \tau}^{-\phi}\right)^{-\alpha /(1-\alpha)}+I_{S}\left(c+h_{s \tau} \bar{Z}_{s \tau}^{-\phi}\right)^{-\alpha /(1-\alpha)}}$ and $s_{N}^{S} \equiv \frac{I_{N}}{I_{N}+I_{S}}$ are value market shares. As $s_{N}^{N}$ increases (decreases) if $\bar{Z}_{N}\left(\bar{Z}_{S}\right)$ increases,

$$
\frac{\partial \hat{\Pi}_{N j \tau}}{\partial \bar{Z}_{N \tau}}>0\left(\frac{\partial \hat{\Pi}_{N j \tau}}{\partial \bar{Z}_{S \tau}}<0\right) .
$$

\subsection{Balanced trade and market clearing conditions}

Trade must be balanced, therefore we have:

$$
I_{N} p_{N \tau}^{S} x_{N \tau}^{S}=I_{S} p_{S \tau}^{N} x_{S \tau}^{N}
$$

Using (4), (5), (9), (10) and the definition of $s_{N}^{S}$ and $s_{N}^{N}$, balanced trade implies:

$$
Y_{S \tau} s_{N}^{S}=\frac{c+(1-\alpha) H_{S \tau}}{\left(c+H_{S \tau}\right)} Y_{N \tau}\left(1-s_{N \tau}^{N}\right)
$$

\footnotetext{
${ }^{3}$ The need for a wage setting mechanism is justified by the fact that in this model there does not exist the traditional perfectly competitive sector that produces an international traded good that, used as numeraire, can pin down relative wages. As we assume here constant returns to scale from labor in both sectors, $\mathrm{X}$ and R\&D (see below section 2.5), labor productivity and income distribution are independent form the size and the allocation of the labor force, hence, this assumption on the wage setting agreement, while rather innocuous, helps to solve the model easily.
} 
where $H_{i \tau} \equiv h_{i \tau} \bar{Z}_{i \tau}^{-\phi}$. Since $\frac{c+(1-\alpha) H_{S \tau}}{\left(c+H_{S \tau}\right)}<1$ in order for (13) to hold it must be that $\frac{Y_{N \tau}}{Y_{S \tau}}>\frac{S_{N}^{S}}{1-S_{N \tau}^{N}}$, that is N's expenditure must be relatively large, and precisely, it must be larger than the relative value of the market shares in the foreign market.

The labor market clearing condition states that labor force in country $i$ must be totally employed in production $\left(L_{X i}\right)$ and research $\left(L_{R i}\right)$, omitting the time subscripts we have:

$$
L_{i}=L_{X i}+L_{R i}
$$

For brevity, let us concentrate on $\mathrm{N}$. The market clearing condition for goods in country $\mathrm{N}$ is:

$$
I_{N} \bar{A}_{N \tau}^{\beta} \frac{L_{X N \tau}}{I_{N}}=I_{N}\left(\hat{x}_{N \tau}^{N}+\hat{x}_{N \tau}^{S}\right)
$$

$\hat{x}_{N \tau}^{i}$ indicates region's $i$ demand for each variety produced in country $\mathrm{N}$ in equilibrium. Combining (14) and (15) and inserting (9) and (10) into (4) and (5), respectively, we have:

$$
\bar{A}_{N \tau}^{\beta} \frac{L_{N}-L_{R N \tau}}{I_{N}}=\frac{\alpha Y_{N \tau} s_{N \tau}^{N}}{I_{N}\left(c+H_{N \tau}\right)}+\frac{\alpha Y_{S \tau} s_{N}^{S}}{c I_{N}} .
$$

Then, combining (13) and (16) we find the allocation of labor between sectors compatible with the resource constraint (RC):

$$
\frac{L_{N}-L_{R N \tau}}{L_{N}}=\frac{\alpha Y_{N \tau}}{I_{N} \bar{A}_{N \tau}^{\beta}}\left[\frac{s_{N \tau}^{N}}{c+H_{N \tau}}+\frac{c+(1-\alpha) H_{S \tau}}{c+H_{S \tau}}\left(1-s_{N \tau}^{N}\right)\right]
$$

As $s_{N}^{N}$ decreases when $H_{N}$ increases, given $Y_{N}$, (17) implies that the proportion of workers employed in production decreases as the green tax increases.

Similarly in S we have:

$$
\frac{L_{S}-L_{R S \tau}}{L_{S}}=\frac{\alpha Y_{S \tau}}{I_{N} \bar{A}_{N \tau}^{\beta}}\left[\frac{s_{N}^{S}}{c+(1-\alpha) H_{S \tau}}+\left(1-s_{N}^{S}\right)\right]
$$

As $s_{N}^{S}$ is independent of the green tax, given $Y_{S}$, an increase in $H_{S}$, tends univocally to reduce the proportion of workers employed in production in $\mathrm{S}$. 


\subsection{Technological change}

To simplify the analysis we assume that the R\&D activity is only carried out by outsiders. ${ }^{4}$ The R\&D process is cumulative, building on the know-how of existing goods. Technology does not diffuse freely, and domestic R\&D labs which hold domestic know-how can only improve domestic technology. In each country there are as many labs as the number of varieties produced domestically. A firm wishing to produce a specific diversified consumption good buys the license to produce with the latest available technology. The firm that uses the latest technology in sector $j$ retains a monopoly right to produce the $j$-th consumption good at that technological level until the next generation of technology arrives. Innovations replace completely older vintages. ${ }^{5}$ The adoption and diffusion of technologies are guaranteed by free entry. ${ }^{6}$ To simplify the analysis, as in Ricci (2007) we assume that each innovation improves both A and Z. More investment in $\mathrm{R} \& \mathrm{D}$ reduces the length of monopoly profits but at the same time increases productivity and reduces the pollution intensity of consumption goods with a positive impact on demand and profits. Technology is improved upon by employing researchers in the labs, the flow of innovations in sector $j$ in a time interval of length $d \tau$ is $\lambda L_{R j \tau} d \tau$, where $L_{R j}$ is the number of workers employed in the $j$-th $\mathrm{R} \& \mathrm{D}$ lab, and $0<\lambda<1$. Using the symmetry assumption of firms within each country, we specify the law of motion for $\mathrm{A}$ and $\mathrm{Z}$ as the following:

$$
\begin{aligned}
& \dot{\bar{A}}_{j i \tau}=\lambda \bar{L}_{R i \tau} \bar{A}_{i \tau} ; 0<\lambda<1 \\
& \dot{\bar{Z}}_{j i \tau}=\theta \bar{L}_{R i \tau} \bar{Z}_{i \tau} ; 0<\theta<1 .
\end{aligned}
$$

A dot over a variable indicates the derivative with respect to time. $\gamma$ and $\theta$ are the shares of R\&D workers that in each lab are devoted to cost-reducing and emissionreducing innovations, respectively, therefore $\gamma+\theta=1$. Constant returns to knowledge

\footnotetext{
${ }^{4}$ Such an assumption would be a natural outcome if incumbents and entrants have the same technology for innovation.

${ }^{5}$ In presence of Bertrand competition, the innovation is drastic if the marginal cost of the incumbent, is greater than the unconstrained monopoly price of entrants, which, absent the green tax is equal to $\frac{c}{\alpha}$. We assume that such a condition is satisfied so that entrants can charge the unconstrained monopolist price.

${ }^{6}$ The replacement effect is at work. Of course, it would be more realistic to assume that R\&D is done inhouse by incumbents; such an assumption would allow us to study the market structure as the outcome of the interplay between incumbents and entrants (Peretto, 2008 and Acemoglu, 2009). However, in a two-country model the analysis would get immediately complicated (see Marconi, 2007) and, since our aim here is to draw first conclusions on the spillovers of a unilateral environmental policy, we want to keep the model as simple as possible.

${ }^{7}$ Such an assumption is indeed required. In fact, for long-run growth to be sustainable technical progress in pollution abatement technology is necessary. Given the symmetry of firms, as entrants replace incumbents on the basis of a better technology, A or Z, on the same product line, they will do so once improvements are achieved on both dimensions. Under this assumption, we are ruling out the possibility that firms with older technologies can survive by serving the unregulated market, which makes even more important to stress the importance of the size of the market where polluting emissions are regulated. For further interpretation and justification of the assumption in case of non-symmetric firms in closed economy see Ricci (2007), note $11 \mathrm{p}$. 292.
} 
accumulation support long-run growth. In order to eliminate strong scale effects from the model, we assume that in each region the number of firms is equal to the population size, that is, $I_{i}=L_{i}{ }^{8}$ If we define the share of the labor force employed in production as $l_{x i} \equiv \frac{L_{X i}}{L_{i}}$ and that employed in $\mathrm{R} \& \mathrm{D}$ as $l_{R i} \equiv 1-l_{x i}$, we then have:

$$
\begin{aligned}
& \frac{\dot{\bar{A}}_{i \tau}}{\overline{\bar{A}}_{i \tau}}=\gamma \lambda l_{R i \tau} \\
& \frac{\dot{\bar{Z}}_{i \tau}}{\bar{Z}_{i \tau}}=\theta \lambda l_{R i \tau} .
\end{aligned}
$$

\subsection{The free-entry and general equilibrium}

By investing an amount of resources equal to $\mathrm{w}_{\tau} L_{R j \tau}$ an innovator in the product line $\mathrm{j}$ produces a flow of innovations equal to $(\theta+\gamma) \lambda L_{R j \tau}$ in the period $(\tau+d \tau)$, which allows her to sell the license to a new entrant to replace the existing monopolist in that product line, therefore gaining the value of the firm, $V_{j(\tau+d \tau)}$. Hence, the free-entry condition requires an innovator to maximize:

$$
\max _{L_{R j \tau}} V_{j(\tau+d \tau)} \lambda L_{R j \tau}-w_{\tau} L_{R j \tau}
$$

Maximization then implies

$$
\begin{aligned}
& V_{j(\tau+d \tau)} \lambda=w_{\tau} ; \\
& \mathrm{W}_{\tau} L_{R j \tau} \geq \lambda L_{R j \tau} V_{j(\tau+d \tau)} \text { with equality if } L_{R j \tau}>0 .
\end{aligned}
$$

Meaning that, the entry cost, equal to the marginal cost of an innovation, must equal the value of the firm if entry is positive.

Domestic capital markets are perfectly competitive and capital does not move internationally. The traditional no-arbitrage condition between alternative investment opportunities must hold in both countries. Along the balanced growth path we know from the Euler equation (6) that the interest rate must be constant, therefore, the equilibrium on the capital market for $d \tau \rightarrow 0$ requires:

\footnotetext{
${ }^{8}$ This assumption can be derived from models such as Peretto (1998), where in equilibrium the number of firms is proportional to the size of the labor force. For a discussion of the scale effect, see Jones (2005).
} 


$$
r V_{j \tau}=\pi_{j \tau}+\dot{V}_{j \tau}-\underbrace{\lambda L_{R j \tau}}_{\begin{array}{c}
\text { flow rate at } \\
\text { which an } \\
\text { incumbent } \\
\text { is replaced }
\end{array}} \quad V_{j \tau} .
$$

Equation (21) states that the return on any stock must equal the return on an equal size investment in riskless bonds; therefore, the capitalized value of the firm must be equal to the flow of profits (plus capital gains) minus the losses that occur when the incumbent is replaced by a new entrant (which happens at the flow rate $\lambda L_{R j \tau}$ ). ${ }^{9}$

Rearranging (21) and dropping time subscripts for brevity, in each country we have:

$$
\frac{\dot{V}_{i j}}{V_{i j}}=r_{i}+\lambda L_{R i j}-\frac{\pi_{i j}}{V_{i j}}
$$
Imposing the free entry condition $\frac{\dot{V}_{i j}}{V_{i j}}=\frac{\dot{w}_{i}}{w_{i}}, i=N, S$; and the symmetry condition we
have:

$$
\frac{\dot{w}_{i}}{w_{i}}=r_{i}+\lambda\left(\frac{L_{R i}}{I_{i}}-\frac{\pi_{i j}}{w_{i}}\right)
$$

From the wage setting behavior, we know that:

$$
w_{N}=c \bar{A}_{N}^{\beta} \text { and } w_{S}=c \bar{A}_{S}^{\beta},
$$

therefore:

$$
\frac{\dot{w}_{N}}{w_{N}}=\beta \frac{\dot{\bar{A}}_{N}}{\bar{A}_{N}} \text { and } \frac{\dot{w}_{S}}{w_{S}}=\beta \frac{\dot{\bar{A}}_{S}}{\bar{A}_{S}} .
$$

The growth rate of wages depends on the growth rate of the average firm's know how in the home country.

Inserting (11), (13), (24) and (25) into (23) and using the Euler's equation (6) and the fact that along the balanced growth path the growth rate of wages must equal that of expenditures, we can write the no-arbitrage condition for a typical firm who wish to enter in $\mathrm{N}$ as:

$$
l_{R N}=\frac{(1-\alpha) Y_{N}}{c \bar{A}_{N}^{\beta} I_{N}}\left[s_{N}^{N}+\frac{c+(1-\alpha) H_{S}}{c+H_{S}}\left(1-s_{N}^{N}\right)\right]-\frac{\rho}{\lambda} .
$$

Similarly in S we have:

\footnotetext{
${ }^{9}$ The transversality condition requires: $\lim _{t \rightarrow \infty}\left[\exp \left(-\int_{\tau}^{t} r(s) d s\right) \sum_{j=1}^{I_{i}} V\left(i, j, t \mid \bar{A}_{i}, \bar{Z}_{j}\right)\right]=0$.
} 


$$
l_{R S}=\frac{(1-\alpha) Y_{S}}{c \bar{A}_{S}^{\beta} I_{S}}\left[\frac{c+H_{S}}{c+(1-\alpha) H_{S}} s_{N}^{S}+\left(1-s_{N}^{S}\right)\right]-\frac{\rho}{\lambda}
$$

Equations (26) and (26') give the allocation of workers between production and R\&D compatible with labor, goods, and capital market clearing conditions in the two countries. In $\mathrm{N}$, the relationship between the green tax and the proportion of workers employed in R\&D is in principle uncertain because, while the terms of trade exert a negative effect, (holding constant $s_{N}^{N}$, the second term in the square bracket of (26) decreases as $H_{S}$ increases), expenditures, in turn, exert a positive effect; in fact, when $H_{i}$ increases $Y_{N}$ increases as well. ${ }^{10}$ In $\mathrm{S}$, instead, $\mathrm{Y}_{\mathrm{S}}$ and $s_{N}^{S}$ are not affected by the green tax, while the terms of trade is positively affected (see the first term in the square bracket of $\left(26^{\prime}\right)$ ). Therefore, from (26') we find that in $S$ the green tax univocally tends to increase the proportion of workers employed in $R \& D$. To find out the general equilibrium along the balanced growth path we need, therefore, to establish the tax strategy of the government in $\mathrm{N}$.

\section{Green Tax Revenues and Balanced Growth Path}

Let us now turn our attention to government policy. The government in setting the green tax can make different choices, however not all of them are compatible with a balanced growth path. Total revenues for the government are $G_{\tau}=I_{N} H_{N \tau} \hat{x}_{N \tau}^{N}+I_{S} H_{S \tau} \hat{x}_{S \tau}^{N}$. By using demand functions (4), price equations (9) and (10), and the definition of $s_{N \tau}^{N}$, revenues can be written as:

$$
G_{\tau}=\alpha Y_{N \tau}\left[\frac{H_{N \tau}}{\left(c+H_{N \tau}\right)} s_{N \tau}^{N}+\frac{H_{S \tau}}{\left(c+H_{S \tau}\right)}\left(1-s_{N \tau}^{N}\right)\right] .
$$

It is easy to see that the only policy compatible with balanced growth path is the one that lets $G_{\tau}$ grow at the same rate of domestic expenditures, and this, in turn, requires keeping constant over time the whole quantity in the square bracket of (27). Hence the government must set $\dot{H}_{N}=\dot{H}_{S}=0$, that is, it must keep constant the revenues per unit of consumption of both domestic and foreign goods over time. Such a policy implies that $s_{N}^{N}$ is constant over time and the tax rates adjust to the change in pollution intensities,

\footnotetext{
${ }^{10}$ The proof is available from the author upon request.
} 
that is, $\frac{\dot{h}_{i}}{h_{i}}=\phi \frac{\dot{Z}_{i}}{Z_{i}}$; if pollution intensities are abated at different speeds then the two tax rates must grow at different rates. ${ }^{11}$

Inserting (27) into the household's budget constraint, solving for $Y_{N}$ and substituting back into (26) we get the balanced growth path (BGP) share of workers in R\&D and the long-run growth rate: ${ }^{12}$

$$
\begin{aligned}
& l_{R N}^{*}=\frac{(1-\alpha)(\rho+\lambda) \psi_{2}-\rho\left(1-\alpha \psi_{1}\right)}{\lambda\left[\left(1-\alpha \psi_{1}\right)\right]} \\
& g_{N}^{*}=\frac{\beta \gamma\left[(1-\alpha)(\rho+\lambda) \psi_{2}-\rho\left(1-\alpha \psi_{1}\right)\right]}{\left(1-\alpha \psi_{1}\right)},
\end{aligned}
$$

where $\psi_{1} \equiv \frac{H_{N}}{\left(c+H_{N}\right)} s_{N}^{N}+\frac{H_{S}}{\left(c+H_{S}\right)}\left(1-s_{N}^{N}\right) ; \psi_{2} \equiv s_{N}^{N}+\left[\frac{c+(1-\alpha) H_{S}}{c+H_{S}}\right]\left(1-s_{N}^{N}\right)$.

Similarly, in $\mathrm{S}$ we have:

$$
\begin{aligned}
& l_{R S}^{*}=\frac{(1-\alpha)(\rho+\lambda) \psi_{3}-\rho}{\lambda} \\
& g_{S}^{*}=\beta \gamma\left[(1-\alpha)(\rho+\lambda) \psi_{3}-\rho\right] \\
& \psi_{3} \equiv \frac{c+H_{S}}{c+(1-\alpha) H_{S}} s_{N}^{S}+\left(1-s_{N}^{S}\right) .
\end{aligned}
$$

When $H_{N}=H_{S}=0$ then $\psi_{1}=0$ and $\psi_{2}=\psi_{3}=1$. When $H_{N}=H_{S}>0$ then $0<\psi_{1}=\frac{H}{c+H}<1,0<\psi_{2}=s_{N}^{N}+\left[\frac{c+(1-\alpha) H}{c+H}\right]\left(1-s_{N}^{N}\right)<1$, and $\frac{\psi_{2}}{\left(1-\alpha \psi_{1}\right)}=\psi_{3}=\frac{c+H}{c+(1-\alpha) H} s_{N}^{S}+\left(1-s_{N}^{S}\right)>1 . \psi_{1}$ represents the saving push induced in $\mathrm{N}$ by government revenues, which tend to increase the share of workers allocated in R\&D in $\mathrm{N} ; \psi_{2}$ and $\psi_{3}$, in turn, capture the terms of trade effects. Such an effect, being negative for $\mathrm{N}$, reduces $\psi_{2}$, thereby shifting workers away from the R\&D sector, towards the production sector; on the contrary, this effect being positive in $\mathrm{S}$,

${ }^{11}$ Note that if the government sets $H_{N}=H_{S}$ and $\dot{H}_{N}=0$, then $\dot{H}_{S}=0$. In fact, $h_{S}=h_{N} \frac{Z_{N}^{-\phi}}{Z_{S}^{-\phi}}$ implies $\dot{h}_{S}=\dot{h}_{N} \frac{Z_{N}^{-\phi}}{Z_{S}^{-\phi}}-\phi h_{N} \frac{Z_{N}^{-\phi}}{Z_{S}^{-\phi}}\left(\frac{\dot{Z}_{N}}{Z_{N}}-\frac{\dot{Z}_{S}}{Z_{S}}\right)$, hence, $\frac{\dot{h}_{S}}{h_{S}}=\frac{\dot{h}_{N}}{h_{N}}-\phi\left(\frac{\dot{Z}_{N}}{Z_{N}}-\frac{\dot{Z}_{S}}{Z_{S}}\right)$. Therefore, if $\frac{\dot{h}_{N}}{h_{N}}=\phi \frac{\dot{Z}_{N}}{Z_{N}}$, then $\frac{\dot{h}_{S}}{h_{S}}=\phi \frac{\dot{Z}_{S}}{Z_{S}}$

${ }^{12}$ The proof is available from the author upon request. 
increases $\psi_{3}$, shifting workers towards the R\&D sector there. Also note that the larger the relative size of $\mathrm{N}$, that is, the larger $s_{N}^{N}$, which under the BGP government policy is equal to $s_{N}^{S}$, the larger are both $\psi_{2}$ and $\psi_{3}$. The following proposition summarizes these findings.

Proposition 1. Suppose the government sets $H_{N}=H_{S}>0$. As $\frac{\psi_{2}}{\left(1-\alpha \psi_{1}\right)}=\psi_{3}>1$ the green tax univocally increases the BGP proportion of workers allocated to $R \& D$ in both countries. In the South, the positive terms of trade effect always guarantees this result. In the North, instead, as two opposite forces are at work, a positive push on savings generated by government revenues, and a negative effect on savings generated by the worsening of the terms of trade, the BGP allocation of workers between the two sectors depends on which one of these two effects prevails. In the case of $H_{N}=H_{S}>0$ the saving push effect prevails. Moreover, the larger the relative size of $N$, the market that regulates, the larger the saving push effect in $N$ and the positive terms of trade effect in $S$, and, therefore, the higher the proportion of workers allocated to $R \& D$ in both countries.

A numerical example based on the values reported in Table 1 confirms that for some combination of parameters and initial conditions the green tax on consumption has indeed the potential to increase the proportion of workers employed in R\&D in both regions (fig.1), inducing a higher rate of pollution abatement innovations in both regions.

Table 1: Initial conditions and parameters for numerical example

\begin{tabular}{|c|c|c|c|c|c|c|c|c|c|c|c|c|}
\hline$L_{N}$ & $L_{S}$ & $A_{N}$ & $A_{S}$ & $Z_{N}$ & $Z_{S}$ & $\beta$ & $\phi$ & $\alpha$ & $\lambda$ & $\gamma$ & $\theta$ & $\rho$ \\
\hline 150 & 100 & 2 & 1,5 & 20 & 15 & 0.5 & 0.3 & 0.5 & 0.3 & 0.5 & 0.5 & 0.03 \\
\hline
\end{tabular}


Figure 1: BGP optimal allocation of workers to $R \& D$, for different initial tax rates $\left(h_{S 0}=h_{N 0} \Rightarrow H_{S}>H_{N}\right)$.

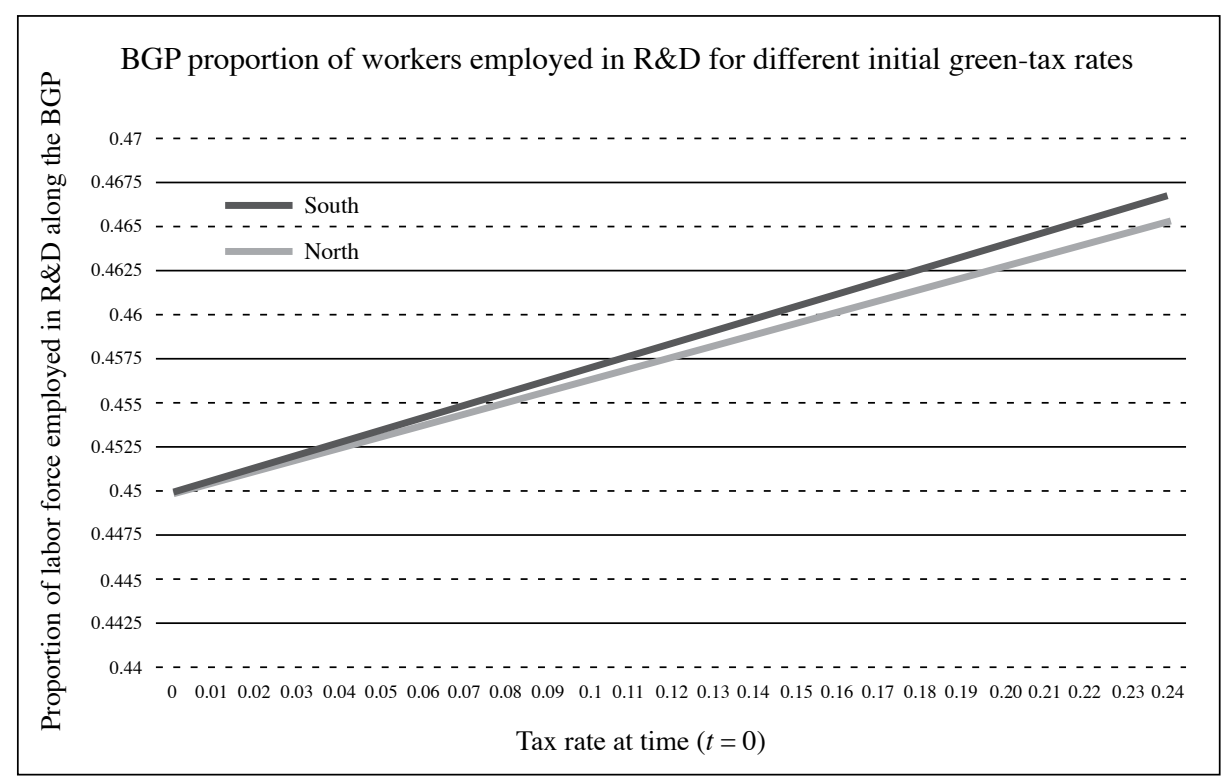

\section{Aggregate pollution}

We now turn our attention to aggregate pollution in both regions. We indicate with $P_{i}^{G}$ the aggregate pollution in region $i$ when the green tax is in place $(\mathrm{H}>0)$ and with $P_{i}^{D}$ the pollution level when the green tax is zero $(\mathrm{H}=0)$ and with a single asterisk BGP levels when $\mathrm{H}>0$ and a double asterisk the BGP levels when $\mathrm{H}=0$. Along the $\mathrm{BGP}$ aggregate pollution will be:

$$
\begin{aligned}
& P_{N \tau}^{G}=\frac{\alpha\left(\beta \gamma \lambda l_{R N}^{*}+\rho+\lambda\right)}{\lambda\left(1-\alpha \psi_{1}\right)} \psi_{4 \tau} A_{N \tau}^{* \beta} I_{N} ; \psi_{4 \tau}^{*} \equiv\left(\frac{1}{c+H_{N}} s_{N}^{N} Z_{N \tau}^{*-\phi}+\frac{1}{c+H_{S}}\left(1-s_{N}^{N}\right) Z_{S \tau}^{*-\phi}\right) \\
& P_{S \tau}^{G}=\alpha\left(\beta \gamma \lambda l_{R S}^{*}+\rho_{+} \lambda\right) \psi_{5 \tau} A_{S \tau}^{* \beta} I_{S} ; \psi_{5 \tau}^{*} \equiv\left(s_{N}^{S} Z_{N \tau}^{*-\phi}+\left(1-s_{N}^{S}\right) Z_{S \tau}^{*-\phi}\right)
\end{aligned}
$$

And for $H_{N}=H_{S}=0$

$$
\begin{aligned}
& P_{N \tau}^{D}=\frac{\alpha\left(\beta \gamma \lambda l_{R N}^{* *}+\rho+\lambda\right)}{\lambda} \psi_{6 \tau}^{* *} A_{N \tau}^{* * \beta} I_{N} ; \psi_{6 \tau}^{* *} \equiv\left(s_{N}^{S} Z_{N \tau}^{* *-\phi}+\left(1-s_{N}^{S}\right) Z_{S \tau}^{* *-\phi}\right) \\
& P_{S \tau}^{D}=\frac{\alpha\left(\beta \gamma \lambda l_{R S}^{* *}+\rho+\lambda\right)}{\lambda} \psi_{6 \tau}^{* *} A_{S \tau}^{* * \beta} I_{S}
\end{aligned}
$$


Proposition 2. As long as $\psi_{4 \tau}^{*}$ and $\psi_{5 \tau}^{*}$ are sufficiently smaller than $\psi_{6 \tau}^{* *}$, a unilateral green tax on consumption can reduce pollution in both countries, that is $P_{N \tau}^{G}<P_{N \tau}^{D}$ and $P_{S \tau}^{G}<P_{S \tau}^{D}$, and can stay lower forever, provided that the pro-growth effect of the green tax does not exceed the pollution dumping effect.

Using the same initial conditions and parameters shown in table 1, we find that the level of pollution, though still increasing over time, is permanently reduced in both countries and therefore worldwide.

Figure 2: World pollution along the BGP when the rate is zero for all consumption goods (WPD $(h=0)$ ), and when $H=0.1$ for all consumption goods (WPG $(H=0.1)$ )

World pollution along the BGP with green tax on consumuption (WPG) and without (WPD)

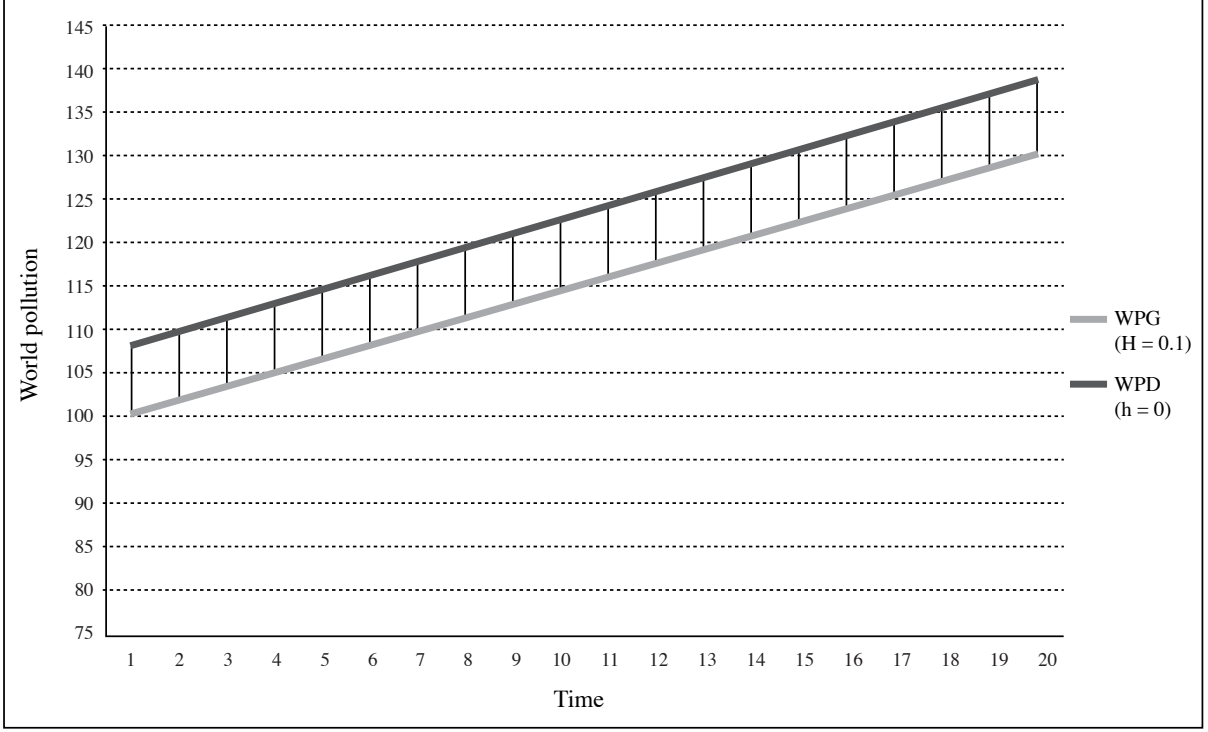

If the elasticity of pollution abatement, $\phi$, is sufficiently large, then the level of pollution might even be constant or decreasing over time and still lower when $\mathrm{H}>0$.

It is worth noting that the pro-growth effect of the green tax arises from the fact that the proportion of $R \& D$ expenditures devoted to the two types of innovations is fixed, so, once resources are shifted from production to $R \& D$, the flow rate of innovation increases for both A and Z. However, such a simplification does not undermine the main result delivered by the model, that is, there exists a positive spillover effect on pollution abatement in the South. 


\section{Welfare}

Suppose the two economies are in a steady state and consider the case $H_{N}=H_{S}$. The instantaneous utility functions derived from (3) and (3') are:

$$
\begin{aligned}
& u_{N \tau}=\frac{1-\alpha(1-\varphi)}{\alpha} \log \left(I_{N}+I_{S}\right)+(1-\varphi) \log \left[\alpha \frac{(\rho+\lambda)}{\lambda}\right]-(1-\varphi) \log \left(1-\alpha \psi_{1}\right)+ \\
& (1-\varphi) \log c-(1-\varphi) \log (c+H)+(1-\varphi) \beta \log A_{N \tau}+(1-\varphi) \log I_{N}- \\
& \frac{\varphi}{\eta} \log \left(I_{N} Z_{N \tau}^{-\phi \eta}+I_{S} Z_{S \tau}^{-\phi \eta}\right) \\
& u_{S \tau}=\frac{1}{\alpha} \log \left(I_{N}+I_{S}\right)+\log \left[\alpha \frac{(\rho+\lambda)}{\lambda}\right]+\beta \log A_{S \tau}+\log I_{S}
\end{aligned}
$$

To compare welfare under the two policy regimes let us denote as before with a single asterisk the BGP levels when $\mathrm{H}>0$ and with a double asterisk BGP levels when $\mathrm{H}=0$. Dropping the time subscripts for brevity, at a given moment in time, the difference between the utility indexes under the two regimes in $\mathrm{N}$ and $\mathrm{S}$ will be given by:

$$
\begin{aligned}
& u_{N}^{*}-u_{N}^{* *}=-(1-\varphi) \log \frac{[c+(1-\alpha) H]}{c}+(1-\varphi) \beta\left[\log A_{N}^{*}-\log A_{N}^{* *}\right]+ \\
& \frac{\varphi}{\eta}\left[\log \left(I_{N} Z_{N}^{* *-\phi \eta}+I_{S} Z_{S}^{* *-\phi \eta}\right)-\log \left(I_{N} Z_{N}^{*-\phi \eta}+I_{S} Z_{S}^{*-\phi \eta}\right)\right] \gtrless 0 ; \\
& u_{S}^{*}-u_{S}^{* *}=\beta\left(\log A_{S}^{*}-\log A_{S}^{* *}\right)>0 .
\end{aligned}
$$

The first term on the right hand side of equation (37) indicates the negative effect on consumption exerted by the green tax in $\mathrm{N}$; however, as $A_{N}^{*}>A_{N}^{* *}$ and $Z_{N}^{*}>Z_{N}^{* *}$ the sum of the other three terms in (37) is positive. Therefore, provided that $\mathrm{H}$ is not too large, welfare in $\mathrm{N}$ can be higher when $\mathrm{H}>0$ comapred to the case in which $\mathrm{H}=0$. As shown by (38), in $\mathrm{S}$ welfare is always higher when $\mathrm{H}>0$; in fact, by the terms of trade effect, wealth is increased so that the region can enjoy both the same level of consumption and a higher rate of productivity growth compared to the case of $\mathrm{H}=0$. We conclude therefore, that:

Proposition 3. A unilateral green tax on consumption can improve welfare and rise the rate of productivity growth and pollution abatement in both regions.

We can also compare the market equilibrium allocation with the socially efficient allocation of workers. We assume that households in $\mathrm{N}$ recognize pollution as a bad but do not internalize their contribution to it. On the contrary, the government internalizes such a contribution and specializes the households' damage function as 
$P_{N \tau}=\left[\sum_{j=1}^{I_{N}+I_{S}}\left(x_{j \tau}^{N} Z_{j \tau}^{-\phi}\right)^{\eta}\right]^{1 / \eta}$. Hence, the government in $\mathrm{N}$ maximizes the following social welfare function $\left(S W_{N \tau}\right)$ :

$$
\begin{aligned}
& \max _{\left\{x_{j}^{\left.N{ }^{*}\right\}_{t}}\right.} S W_{N \tau}= \\
& \int_{t}^{\infty} e^{-\rho(\tau-t)}\left\{\log \left[\sum_{j=1}^{I_{N}+I_{S}}\left(x_{j \tau}^{N}\right)^{\alpha}\right]^{1 / \alpha}-\varphi \log \left[\sum_{j=1}^{I_{N}+I_{S}}\left(x_{j \tau}^{N} Z_{j \tau}^{-\phi}\right)^{\eta}\right]^{1 / \eta}\right\} d \tau
\end{aligned}
$$

subject to the technology constraint (7), the market clearing constraints (12), (14) and (15) and the low of motions (18'). Solving the social planner problem we find the social optimal allocation of workers between the two sectors. If the social optimal share of workers in R\&D is larger than the decentralized market equilibrium's one, the government can find the level of $H$ that sets the two equal. To simplify the calculations, let us consider the case of symmetric countries. In this case, the social optimal share of workers to be employed in $\mathrm{R} \& \mathrm{D}$ is given by:

$$
l_{R}^{S P^{*}}=\frac{(1-\varphi)(\beta \gamma \lambda-\rho)+\varphi \phi \theta \lambda}{\lambda[\gamma \beta(1-\varphi)+\theta \varphi \phi]} .^{13}
$$

The superscript SP indicates that (39) is the social planner optimal allocation. We can now compare (39) with the market optimal allocation when countries are symmetric and $\mathrm{H}=0$ (call it MD):

$$
l_{R}^{M D^{* *}}=\frac{(1-\alpha) \lambda-\alpha \rho}{\lambda} .
$$

The social optimal proportion of workers employed in R\&D, given by (39), might be larger or smaller than the market allocation, given by (40), depending on the parameters of the economy. ${ }^{14}$ For example, using the numbers reported in table 1 and setting $\varphi=0.1$, we find that the social planner optimum would be equal to 0.63 , which is larger than the decentralized one, equal to 0.45 ; in such a case the government can reach the social optimum by setting $H$ at the level that sets the two shares equal.

\footnotetext{
${ }^{13}$ The derivation is available from the author upon request.

${ }^{14}$ In the case of a Shumpeterian endogenous growth model, it might be possible that the market equilibrium leads to too much investment in R\&D than the social optimum would require. In general, this happens if the appropriability effect is lower than the business stealing effect (Acemoglu, 2009). In our case, however, more considerations need to be done: on the one side, the value of R\&D is not fully appreciated by the market since innovations that improve the pollution abatement technology is not really valued until the government introduces a pollution tax, on the other side, however, by increasing the proportion of labor force employed in R\&D the long-run growth rate increases as well, counteracting the pollution abatement effect; therefore, the social planner must balance these two effects. The other major difference between the social planner and the decentralized solutions is in that in the former R\&D is equivalent to an in-house activity, whereas in the latter only outsiders do it; hence the steady state expressions look very different.
} 


\section{Conclusion}

Climate policies have become a major issue in the agenda of policymakers worldwide, in recognition of the global threat posed by global warming and climate change. The industrialized world is considered the main party responsible for global warming to date and is asked to take the lead in implementing mitigation policies (Giddens, 2009). However, unilateral actions in a globalized world are opposed on the basis of competitiveness concerns, free-riding behaviors and carbon-leakage considerations. Competitiveness concerns stem from the fact that greenhouse gas emissions are primarily seen as a by-product of production. In such a case, unilateral actions in pollution abatement would impose additional costs on domestic firms, likely causing a simple relocation of production and polluting emissions in countries with lower environmental standards (carbon leakage in pollution havens).

By shifting the attention from pollution as a by-product of production to pollution as a by-product of consumption, in this paper we show that, indeed, a unilateral green tax on consumption could overcome competitiveness and carbon leakage problems, rising welfare and abating pollution worldwide. This outcome is precisely the result of the fact that a green tax on consumption affects both domestic and import prices in the same fashion. For such an action to be successful, however, market size is essential, in that only a large and rich market can offer the right incentives to invest in new technologies affecting world innovation and pollution abatement.

These results, even though obtained within a very stylized model, highlight that taxes on consumption, and consumption behavior more in general, should deserve more attention in the environmental policy debate.

\section{References}

Acemoglu, D., 2009, Introduction to modern economic growth (Princeton University Press: Princeton and Oxford).

Albrect, J., 2006, "The use of consumption taxes to re-launch green tax reforms", International Review of Law and Economics 26, 88-103.

Copeland, B.R. and M.S. Taylor, 1995, "Trade and the environment: A partial synthesis", American Journal of Agricultural Economics 77(3), 765-771.

Copeland, B.R. and M.S. Taylor, 2003, Trade and the environment (Princeton University Press: Princeton and Oxford).

Copeland, B.R. and M.S. Taylor, 2004, "Trade, growth and the environment”, Journal of Economic Literature 42, 7-71.

Copeland, B.R. and M.S. Taylor, 2005, "Free trade and global warming: a trade theory view of the Kyoto protocol", Journal of Environmental Economics and Management 42 (2), 205-34.

Di Maria, C. and S.A. Smulders, 2004, "Trade permits vs. technology optimists: Induced technical change and pollution havens", Advances in Economic Analysis \& Policy, 4 (2), art.7. Available at http://www.bepress.com/bejeap

Giddens, A., 2009, The politics of climate change (Polity Press: Cambridge, UK). 
Jones, C.J., 2005, "Growth and ideas", in P. Aghion and S. Durlauf, eds, Handbook of Economic Growth, Vol. 1B (Elsevier B.V.), 1064-1108.

Marconi, D., 2007, "Endogenous growth and trade liberalization between asymmetric countries", Bank of Italy, Temi di Discussione 630.

McAusland, C., 2008, "Trade, politics, and the environment: Tailpipe vs. smokestack", Journal of Environmental Economics and Management 55, 52-71.

Milito, A. C. and G. Gagnon., 2008, "Greenhouse gas emissions - a focus on Canadian households", EnviroStats Winter 2(4), 3-6.

OECD, 2008, Consumption tax trends 2008 (OECD: Paris).

Peretto, P., 1998, "Technological change and population growth", Journal of Economic Growth 3(4), 283-311.

Peretto, P., 2008, "Effluent taxes, market structure, and the rate and direction of endogenous technological change", Journal of Environmental Economics and Management 39, 113-138.

Ricci, F., 2007, "Environmental policy and growth when input are differentiated in pollution intensity", Journal of Environmental Economics and Management 38, 285-310.

Schleich, J., 1999, "Environmental quality with endogenous domestic trade policies", European Journal of Political Economy 15, 53-71. 